\title{
Tecnologias de informação e comunicação na educação: mudanças e inovações no ensino superior
}

Guilherme Paiva de Carvalho Martins

Curso: Doutorado em Sociologia

Data da defesa: 30 de março de 2009

Orientadora: $\operatorname{Prof}^{\mathrm{a}} \mathrm{Dr}^{\mathrm{a}}$ Fernanda Antonia da Fonseca Sobral

\section{Resumo}

A pesquisa teve como objetivo analisar as mudanças na Educação a Distância (EAD) no ensino superior público brasileiro com a difusão e o uso de tecnologias de informação e comunicação (TICs). Para tanto, investigamos experiências de universidades públicas brasileiras, dados quantitativos e qualitativos concernentes à EAD, tomando como referência o período de 1990 a 2006. Para compreender o ponto de vista de educadores do ensino superior, analisamos discursos de gestores/as e professores/as que trabalham com esta modalidade educacional e professores/as que não trabalham com ela na Universidade de Brasília, na Universidade Federal do Mato Grosso e na Universidade Federal do Ceará.

Os resultados da pesquisa evidenciaram inovações nas práticas educacionais, dificuldades e problemas enfrentados por profissionais envolvidos com a $\mathrm{EAD}$, além da formulação de políticas públicas no ensino superior brasileiro. $\mathrm{O}$ trabalho evidenciou mudanças no ensino superior com o uso de TICs, sobretudo no tocante ao aumento do número de cursos de graduação e ampliação de vagas no ensino superior brasileiro, bem como na produção de materiais didáticos 
para cursos de EAD. Estes materiais potencializam a interatividade entre professores, tutores e alunos, inovando as práticas educacionais. Com a inserção de TICs no ensino superior, universidades, órgãos governamentais e empresas formam parcerias para oferecer cursos. De acordo com o ponto de vista de gestores/as e professores/as que trabalham com a EAD, esta modalidade é vista como uma forma de democratização do conhecimento, além de proporcionar a qualificação profissional, fator essencial para o desenvolvimento socioeconômico no contexto da globalização.

O estudo mostrou que, no ensino superior brasileiro, existem controvérsias em torno da EAD. Durante a pesquisa, foi possível conhecer experiências com a EAD na Universidade Aberta de Portugal, na Universidade Nova de Lisboa, na Universidad Nacional de Educación a Distancia da Espanha e no Centre National de l'Enseignement à Distance (CNED) da França, graças ao doutorado sanduíche da Universidade Nova de Lisboa.

Palavras-chave: tecnologia; educação a distância; ensino superior; inovação. 